\title{
BERNARD FLYNN, LEITOR DE CLAUDE LEFORT ${ }^{1}$
}

\author{
Silvana de Souza Ramos ${ }^{2}$
}

Resumo: Claude Lefort é um dos mais inovadores filósofos políticos de nossa época. Sua obra apresenta-se em grande parte, excetuando-se o livro dedicado a Maquiavel, por meio da compilação de ensaios escritos em períodos diversos e que giram em torno de problemas centrais, especialmente a caracterização da democracia e do totalitarismo. A tarefa de dar sentido a este projeto filosófico, dado o seu caráter assistemático, é bastante difícil. Assim, o trabalho de Bernard Flynn mostra-se extremamente fecundo para a interpretação do pensamento de Lefort. Ele defende que a junção entre a fenomenologia, filosofia que permite dissecar nosso acesso ao real ao interpretar a experiência vivida no interior do dispositivo simbólico democrático, e a leitura da tradição da filosofia política, capaz de produzir uma interpretação dos acontecimentos que marcam a modernidade, permite a Lefort criar uma nova compreensão do político. Este artigo pretende apresentar os principais aspectos dessa interpretação da obra de Lefort.

Palavras-chaves: Claude Lefort - Bernard Flynn - democracia - simbólico - imaginário - real.

A obra de Claude Lefort tem despertado maior interesse nos últimos anos por apresentar uma alternativa à reflexão e à análise da democracia moderna, uma vez que conjuga a matriz filosófica trazida pela fenomenologia, especialmente aquela de MerleauPonty, aos estudos da tradição da filosofia política. Lefort não pretende apenas tentar compreender o caráter comunicativo inerente à constituição de um espaço público de debate, pois investiga a democracia como uma experiência moderna, a qual envolve um modo peculiar de relação entre os indivíduos incapaz de sustentar uma identidade fechada tanto destes, considerados um a um, quanto do corpo da sociedade. Trata-se de investigar, sob vários aspectos, a mutação simbólica capaz de abrir o horizonte para essa nova experiência. Bernard Flynn é sensível a essa postura inerente ao pensamento de Lefort e, especialmente em seu livro The Philosophy of Claude Lefort. Interpreting the Political, raro exemplo de um trabalho de fôlego dedicado ao pensador francês, busca elucidar o caminho

\footnotetext{
${ }^{1}$ Dossiê Claude Lefort: esse texto é parte do dossiê publicado a partir das comunicações realizadas no Colóquio Internacional Claude Lefort: a invenção democrática hoje, realizado na Universidade de São Paulo entre os dias 13 e 16 de outubro de 2015.

2 Professora Doutora de Faculdade de Filosofia Letras e Ciências Humanas da Universidade de São Paulo

(FFLCH- USP). E-mail: ramos_si@hotmail.com
} 
percorrido por Lefort - desde seus primeiros ensaios, publicados no período de formação do filósofo, passando pelo volumoso estudo sobre Maquiavel, primeira grande síntese realizada pelo autor, até os escritos finais onde se articulam a teoria da democracia e a análise do totalitarismo. O percurso traz à tona as marcas do nascimento da modernidade, a partir de elementos pré-modernos, quando se desfaz a eficácia prática e teórica da representação unitária do corpo político, quando vem à tona o sujeito portador de direitos universais, contrário à demarcação de privilégios sociais e políticos, e quando se transforma a relação da sociedade com o aspecto transcendente do lugar do poder.

Dividido em quatro partes, o livro de Flynn enfatiza primeiramente a abordagem assumida por Lefort enquanto leitor de Maquiavel - aqui, a ideia de leitura tem um caráter fundamental, pois estabelece um elo com o trabalho da obra do florentino, seu engajamento com os problemas da época, os conflitos e embates que permeavam a experiência florentina do século XV, e sua consequente capacidade de nos ajudar a desvendar a modernidade vindoura; na segunda parte, o autor confronta Lefort com a noção de prémodernidade, tanto no que se refere aos povos sem Estado quanto à forma do político expressa na Europa pelo Ancien Régime; na terceira, desvenda os traços definidores da modernidade, quando as revoluções do século dezoito dão azo ao lugar vazio do poder, dando nascimento à democracia, ao mesmo tempo em que separam as esferas do Poder, da Lei, e do Saber; por fim, na quarta parte do livro, Flynn disseca a interpretação lefortiana do totalitarismo enquanto uma contrarrevolução relativa à democracia.

Ao abordar a leitura de Maquiavel engendrada por Lefort, Flynn mostra que o conceito de obra tem um sentido bastante peculiar, ligado à ideia merleau-pontiana de engajamento. A obra não é um objeto fechado sobre si mesmo, ao contrário, ela é a abertura de um horizonte de pensamento não totalizável. Esse horizonte é reaberto e redirecionado pelos leitores, de modo que o trabalho da obra se desdobra por meio das diferentes perspectivas de leitura que se desenham ao longo da história de sua recepção. Ao retomar uma obra, tal como a de Maquiavel, damos continuidade diferenciada a esse trabalho, pois nosso acesso ao seu sentido é vislumbrado em meio às interpretações que precederam a nossa, e que foram geradas por ela. A presença da obra para nós é, ao mesmo tempo, presença dos leitores que se debruçaram sobre ela, ainda que muitos deles tenham produzido caminhos interpretativos diversos daqueles que se abrem para nós. Nestes termos, essa presença é marcada pela indeterminação, por uma quase-presença irredutível, ou, ainda, segundo os termos de Merleau-Ponty, sua visibilidade, desenhada pela leitura, é permeada por uma invisibilidade que nunca se esgota, invisibilidade que suscita outras 
interpretações. Não sendo um objeto fechado sobre si mesmo, a obra não apresenta limites definidos, ao contrário, ela se desdobra pelo trabalho do leitor, o qual constrói-se por meio da leitura e a partir de sua própria experiência histórica. Assim, a interpretação não é apenas a confrontação direta com um manuscrito, pois participa da instituição de um estilo não apenas de pensamento como também de relação com o real e com a história. A leitura envolve, portanto, o engajamento do leitor na produção crítica de um sentido trazido pelo confronto com a obra, o qual tanto incide sobre os acontecimentos passados quanto ilumina a experiência presente.

No caso específico de Maquiavel, constrói-se em torno do autor o mito do homem maquiavélico, adjetivação de um nome que teria a função de expressar o desencantamento do mundo, quando a ordem pré-moderna se dessacraliza, trazendo consigo a consequente angústia que acomete tal experiência. $\mathrm{O}$ mito encena a ficção do poder maquiavélico, segundo uma dupla intenção. De um lado, nomeia a perda da substância da sociedade, quer dizer, a dissolução dos laços que uniam o poder político à totalidade da existência humana e, de outro lado, expressa a consequente ameaça gerada por essa dissolução, quando a sociedade não mais crê em sua própria unidade. Esse mito demarca, portanto, um advento articulado ao nascimento da modernidade, qual seja, a desencarnação da sociedade, a qual se mostra incapaz de camuflar ou mesmo de deter os conflitos que a atravessam. Em suma, o trabalho da obra de Maquiavel está relacionado à sensibilidade do autor para a transcendência do poder, não mais fundada em Deus ou na natureza, e, por isso mesmo, desenhada a partir de uma experiência política atravessada pelo conflito, pela indeterminação e pela angústia. O mito do homem maquiavélico é, assim, o duplo da obra de Maquiavel, pois, por meio do homem maquiavélico, ele figura um responsável pela dissolução moderna da identidade, vislumbrada pelo florentino. Assim, esse mito é ao mesmo tempo um esforço no sentido de mascarar essa perda, embora seja, no limite, a reverberação mais contundente do desconforto consequente a essa dessubstancialização do social.

Decerto, Maquiavel permite a Lefort entender as dimensões políticas da sociedade moderna ao mesmo tempo em que filosoficamente estabelece uma íntima conexão entre os conceitos de modernidade e de discurso político. Apenas na modernidade se torna possível investigar a origem da sociedade e do poder. Assim, por um lado, ambos, discurso e político, aparecem acoplados e são constitutivos de uma certa experiência social, aquela em que o poder não mais encontra uma fundamentação última que lhe daria uma legitimidade inquestionável. Por outro lado, a meditação lefortiana sobre a modernidade e o político se 
constrói sobre o pano de fundo de uma investigação sobre o pré-moderno em dois sentidos: a consideração das chamadas sociedades sem história, a partir de uma leitura dos estudos antropológicos de Mauss, Mead, Kardiner, Clastres, entre outros, e pela análise da presença do teológico-político, isto é, da articulação entre o cristianismo e a monarquia europeia. Nos dois casos, segundo a leitura apresentada por Flynn, Lefort investiga o papel representado pela transcendência na configuração da experiência política. Afinal, por meio de uma relação peculiar com a transcendência, a modernidade inaugura o discurso político, ao mesmo tempo em que abre o horizonte de uma experiência verdadeiramente histórica. Vejamos como isso se dá.

A segunda parte do livro de Flynn se atém, primeiramente, à interpretação lefortiana das chamadas sociedades primitivas ou sem história, as quais têm sua estrutura simbólica atada à natureza ou a um mundo suprassensível, isto é, a outro lugar. Resta saber como essa referência à exterioridade se articula ao surgimento da Lei. Ora, diferentemente de Clastres, por exemplo, o qual considera que a transcendência do poder é um acontecimento trágico - marcado historicamente pelo surgimento do Estado, cujo resultado é a impossibilidade de a comunidade política permanecer num regime de autogestão -, Lefort defende que mesmo as sociedades sem história - ou contra o Estado mantêm essa referência a outro lugar. Decerto, a própria descrição feita pelo antropólogo francês dos rituais que trazem à existência a Lei pode levar a duas conclusões distintas. Para Clastres, a inscrição ritualizada da Lei permite à sociedade primitiva resistir à separação entre a comunidade política e o exercício do poder. Noutros termos, o poder é imanente à sociedade e é isto que a diferencia daquelas sociedades em que se instituiu o poder transcendente do Estado. Para Lefort, ao contrário, não há sociedade sem referência à transcendência. Mesmo as sociedades primitivas, como no caso das que se valem de rituais que inscrevem a Lei nos corpos dos indivíduos, testemunham um entrecruzamento entre este mundo e um outro, natural ou sobrenatural, de modo que a auto inscrição destas, enquanto sociedades, implica uma relação com a alteridade.

Ora, Clastres mostra que a divisão social e o conflito não estão ausentes nas sociedades sem história, ao contrário, a estrutura simbólica destas permite que elas os neguem e se defendam deles. A Lei, impressa pelo ritual, reza, por exemplo, que ninguém vale mais que os demais membros da sociedade, tampouco vale menos. Essa Lei tem força suficiente para defender a sociedade de qualquer conflito interno e, ainda, da possível ascensão de um indivíduo que assumiria um poder coercitivo a ser exercido sobre os demais. Lefort argumenta que embora o corpo sobre o qual se inscreve essa Lei seja um 
corpo natural - o corpo dos indivíduos que compõem a sociedade estruturada segundo uma forma específica de relações -, devemos considerar que esse corpo é também habitado por forças exteriores que o atravessam, forças que fornecem um escopo simbólico transcendente à sociedade, isto é, que lhe fornecem a Lei estruturante a partir do qual ela se ordena internamente. Em outras palavras, enquanto Clastres analisa o ritual de inscrição da Lei segundo uma perspectiva que acentua a recusa dessa sociedade em permitir que qualquer poder dela se desprenda e, assim, converta-se em uma entidade independente, a exemplo do Estado, Lefort procura mostrar que essa igualdade radical entre os membros da sociedade - já que aí não se estabelece uma relação de mando e obediência - não abole a referência à alteridade. A Lei vem de outro lugar, e é ela que dá sentido às relações igualitárias entre os membros da sociedade ao inscrever um interdito a partir do qual ela se estrutura simbolicamente.

Ora, segundo Lefort, uma das características definidoras das sociedades prémodernas é o apego a certas formas de referência à alteridade que as impelem a constantemente responder ao imperativo de manutenção da estabilidade social. Ao recusar a desigualdade, a coerção e o conflito, essa forma do social remete a Lei a um passado absoluto que se repete no presente, e também no futuro, sem se alterar. Por consequência, essas sociedades não adentram a história, pois tendem a reger-se por uma temporalidade cíclica. Do ponto de vista simbólico, isso significa que não há aí lugar para o questionamento acerca da origem do poder e da Lei, pois esta origem nunca se desvela do interior dessa forma social, ou, melhor dizendo, ela nunca se oferece ao questionamento e ao discurso. Apenas na modernidade essa questão sobre a origem se torna possível. Mais que isso: a modernidade se estrutura a partir da impossibilidade de detê-la. Ao proteger-se do conflito, pois a denegação deste é, de certo modo, a aceitação de sua existência e de seu perigo para a ordem estabelecida, a Lei na sociedade pré-moderna, ao contrário, obscurece essa origem remetendo-a a uma fonte externa - as forças naturais ou sobrenaturais -, a qual dá corpo e forma ao social; dá-lhe, ainda, uma identidade ao fornecer-lhe uma imagem unificada de sua quase-presença enquanto sociedade.

A segunda parte do livro de Flynn dá continuidade a essa leitura ao investigar o funcionamento do Ancien Régime. A pré-modernidade europeia, segundo sua estrutura simbólica, pode ser lida em termos semelhantes àqueles utilizados para abordar as sociedades primitivas, ao menos com referência à posição de outro lugar. Através da imagem mística do corpo do rei, as sociedades da Europa pré-moderna se representavam a si mesmas, embora seja preciso considerar a estruturação destas de modo mais específico. $\mathrm{O}$ 
corpo místico do rei, duplicação de seu corpo natural, figura a unidade da própria nação. Há, porém, um elemento que precisa ser considerado aqui. Se, por um lado, esse corpo místico tem um papel fundamental na medida em que se torna capaz de funcionar como um foco onde a sociedade encontra uma projeção de unidade, por outro lado, essa projeção, ao manter a referência ao divino, pois ele estabelece uma intersecção entre as operações do poder e sua fonte divina de legitimação, expressa um excesso da sociedade em relação a si mesma. Dito de outro modo, embora o corpo místico do rei seja aquilo que permite a essa sociedade representar-se a si mesma, tal representação não fecha ou esgota seu sentido, pois aponta para a transcendência divina. Lefort busca, portanto, compreender a estrutura simbólica aí configurada e caracterizada pelo teológico-político, assunto longamente abordado no ensaio "Permanence du théologico-politique?" (Lefort, 1986, p. 275-329), no qual Flynn se apoia para construir sua interpretação deste ponto. Não se trata de defender o caráter religioso do poder, mas sim de mostrar que a mise-en-forme pela qual o Ancien Régime se institui exige o engendramento de um sentido, uma mise-en-sens, e isto quer dizer que embora a sociedade nunca seja transparente para si mesma, ele se configura por meio de um sistema de significados entrecruzados. O encontro entre o teológico cristão e o político produz um regime, isto é, uma forma do social que aparece como um princípio que pode explicar um modo específico de diferenciação e de articulação entre classes, grupos e traços sociais. O regime ordena, portanto, a experiência da coexistência no interior dessa sociedade, por dar-lhe forma e sentido, e, ainda, por fornecer fundamento para o lugar ocupado por cada um naquela estrutura social e política. Ao mesmo tempo, ele permite uma mise-en-scène, isto é, uma quase-representação dessa sociedade para si mesma, e aqui o corpo místico do rei tem papel fundamental, pois ele tanto remete a origem da Lei à transcendência divina quanto unifica a nação, dando-lhe corpo e unidade. Mais uma vez, o conflito é denegado no mesmo passo em que a origem do poder e da Lei se vê camuflada e afastada de qualquer questionamento, características típicas de sociedades pré-modernas. O resultado disso é que tal sociedade está presa a uma interpretação imaginária do simbólico, já que a projeção de unidade da nação no corpo místico do rei lhe fornece uma figura de mediação capaz de encarnar sua quase-representação ou mise-en-scène. Presa a uma visão imaginária do simbólico, ela se mostra incapaz de produzir um discurso político sobre a origem do social, ou mesmo da Lei, pois o simbólico é pré-determinado pelo imaginário de modo que a abertura ao mundo se torna limitada por essa figuração. Neste sentido, o Ancien Régime denega a divisão social e detém o avanço histórico, pois se ancora numa temporalidade repetitiva e, portanto, fechada à invenção. 
A agudeza de Flynn se expressa na capacidade de mostrar que, segundo Lefort, a modernidade elimina essa interpretação imaginária do simbólico, abrindo à experiência uma nova forma de acesso ao real. A pré-modernidade, tanto no caso das sociedades ditas primitivas quanto no caso do Ancien Régime, se caracteriza politicamente por uma espécie de eclipse que recobre as dimensões real, imaginária e simbólica do poder. Isso significa que essas dimensões são, portanto, invisíveis do interior dessas sociedades, uma vez que se misturam no contexto dessa experiência social e política. Somente a modernidade se torna capaz de enxergá-las e de compreendê-las por meio do discurso. É neste ponto que a experiência moderna do político e o surgimento de um novo tipo de discurso se encontram, dando testemunho do nascimento da modernidade, em contraposição ao que lhe antecede e ao que surgirá com o totalitarismo vindouro. Na sociedade moderna, ao contrário da pré-moderna, não existe uma figura de mediação capaz de encarnar a quasepresença ou a quase-representação da sociedade, ou sua mise-en-scène. Essa sociedade mantém a referência a outro lugar, porém, a transcendência não é ocupada por uma imagem ou por alguém que encarne a articulação entre a sociedade e a fonte transcendente da Lei, e, sendo assim, esse lugar permanece sendo um lugar vazio.

Não há sociedade sem conflito interno, e isso vale tanto para as sociedades prémodernas, quanto para as modernas. Nos dois casos, qualquer figuração de unidade visa dar corpo e imagem àquilo que é atravessado pela contradição, e que não poderia, portanto, caber inteiramente em uma imagem unificadora do social. Ora, a modernidade desfaz o enigma da origem ou da instituição da sociedade, de modo que a transcendência vazia ou inocupável é o correlato da visibilidade do conflito e da indeterminação que atravessam o social. É neste sentido que podemos compreender o desencantamento do mundo ou a dessubstancialização da sociedade moderna ou, ainda, sua desincorporação. É por isso que Maquiavel tem aqui um papel fundamental, pois o florentino foi capaz tanto de dissecar a origem do poder e da Lei, ao mostrar que eles remetem ao conflito social, quanto de explicitar o papel do imaginário e do simbólico na interpretação do real. Maquiavel pôde ver para além de seu tempo, e, nestes termos, ele produziu um dos mais importantes discursos políticos, central para compreender a modernidade, quando simbólico e imaginário se dissociam na leitura e na experiência do real.

E com isso chegamos aos dois últimos aspectos da obra de Lefort analisados por Flynn. Trata-se de compreender a dimensão simbólica da democracia e de mostrar que o totalitarismo é uma contrarrevolução relativa à mutação operada por ela. 
Ora, tanto a democracia quanto o totalitarismo são fenômenos especificamente modernos, pois não encontram equivalentes nas sociedades pré-modernas. Comecemos pela abordagem da democracia, investigação que ocupa a terceira parte do livro de Flynn. Para Lefort, insiste o intérprete, a democracia antiga definia o cidadão segundo certas características de modo que a maior parte da população estava por definição fora do campo da atuação política. $\mathrm{Na}$ democracia moderna, ao contrário, o cidadão é indeterminado, pois sua natureza não pode ser definida pelo gênero, raça, ou classe, por exemplo. O resultado dessa operação é a universalização da cidadania enquanto horizonte da experiência democrática, e a proclamação de direitos inalienáveis, os quais são o mote de uma luta interminável por novos direitos. Dito de outro modo, a modernidade não define o cidadão e, por isso, abre um horizonte de universalidade da cidadania, horizonte que pode, portanto, ser ampliado por meio da conquista de novos direitos. A indeterminação do cidadão e a abstração dos direitos universais configuram a possibilidade de uma luta democrática no interior da sociedade, luta que tem em vista a conquista de liberdades, cujo conteúdo não está previamente circunscrito pelos direitos fundamentais. Trata-se de compreender que essa indeterminação do escopo da cidadania insere a sociedade democrática na história, pois sua Lei de fundação não tem força identitária capaz amarrá-la à temporalidade cíclica da repetição.

O mesmo se pode dizer do conflito social. Denegado pela experiência pré-moderna cuja estrutura simbólica se vê eclipsada por uma interpretação imaginária inquestionável, tal conflito é trazido à tona pela democracia. Assim, numa sociedade democrática, o lugar simbólico da identidade permanece vazio, pois o lugar do poder - enquanto referência a algo transcendente - apenas pode ser ocupado por um tempo determinado e segundo regras que dão legitimidade tanto a sua ocupação quanto ao seu questionamento, de modo que o exercício do poder assume uma exterioridade com relação a si mesmo. Esse lugar não oferece à sociedade uma imagem de si mesma, pelo contrário, a modernidade apaga a figura, porém, não dissolve a dimensão do Outro. Essa dimensão, contudo, não pode materializar-se tampouco ser encarnada por um elemento determinado. Permanecendo indeterminado, o Outro é a expressão simbólica de uma sociedade permeada por diferenças e por conflitos internos, de modo que, na democracia, a fonte de legitimidade do regime é o povo, embora este permaneça sem nome e sem rosto. O resultado dessa equação é que o polo do poder é inocupável, e, embora este seja, segundo dissemos acima, exercido temporariamente e segundo regras, sua legitimidade está sempre sujeita ao questionamento. Noutros termos, na democracia, a identidade e a autoridade estão sempre em questão. 
Assim, na relação com seus representantes, a sociedade constantemente se pergunta, afinal, "quem somos?”, "e quem fala por nós?”, de modo que se torna inviável assumir aí qualquer substancialidade tanto do representante quanto do representado. O mesmo se passa no âmbito do Direito, pois, uma vez que este não se ancora no divino, e dado que os modos de existência, de atividade e de comunicação, cujos efeitos são indeterminados, estão fora de uma órbita meramente coercitiva do poder, a sociedade democrática acaba por suportar um constante questionamento acerca do justo e do injusto. Por fim, no que se refere ao saber, este não provém de uma instância última que forneceria os parâmetros do certo e do errado, pelo contrário, seu âmbito de produção se torna independente do poder, ao mesmo tempo em que a produção de conhecimento e a livre circulação da palavra aparecem como um direito inalienável. É nestes termos que podemos compreender a separação entre Direito, Poder e Saber no interior da democracia assim configurada.

O totalitarismo, por sua vez, não pode ser confundido com a experiência clássica do regime tirânico. A quarta e última parte do livro de Flynn mostra que a chave lefortiana de sua compreensão reside na impossibilidade deste regime de abarcar qualquer transcendência e, ainda, na denegação ou recalque do conflito no interior da sociedade. Não é a presença de um tirano o que define o regime totalitário, mas sim a recusa da indeterminação em todos os âmbitos. Vimos que nas sociedades pré-modernas, a estrutura simbólica está fixada em outro lugar, fora do tempo, seja em um tempo anterior ao tempo, a origem divina da Lei, seja a um mundo invisível pleno de forças naturais ou sobrenaturais. A democracia, por sua vez, esvazia o lugar do poder, e, por consequência, a própria fonte da Lei, sem com isso fazer desaparecer a referência a outro lugar. Ora, o projeto totalitário deseja preencher esse vazio com o corpo inteiro da sociedade tal como esta se encarna no partido ou no líder. Ele busca, portanto, restabelecer os indicadores de certeza, de certo modo vigentes na pré-modernidade, por meio da criação de um discurso inquestionável. $O$ totalitarismo é, por isso mesmo, uma contrarrevolução operada no interior da democracia com vistas a dissolver seu marco simbólico ancorado tanto na indeterminação do povo quanto na dissolução de qualquer soberania inquestionável. O regime totalitário é uma contrarrevolução na medida em que suspende a relação com a transcendência, e a imagem que melhor lhe dá corpo é a da máquina. A sociedade aí se representa como uma vasta organização na qual cada parte atua sobre a outra por meio de uma espécie de causalidade mecânica. Assim se desfaz, por exemplo, a distinção entre o público e o privado, de modo que esse projeto pretende a tudo politizar. O projeto totalitário fecha a sociedade sobre si mesma, e, por consequência, produz uma condensação entre as dimensões da Lei, do Saber 
e do Poder. No regime democrático, surge um debate sobre o que é legítimo ou ilegítimo, debate sem termo último, pois a luta por direitos é um horizonte histórico sem fim determinado. Uma vez que o totalitarismo busca condensar Poder, Lei e Saber, ele pretende, ao contrário, ancorar as decisões sobre o legítimo e o ilegítimo no conhecimento das leis da história, no caso do stalinismo, ou no conhecimento das leis da raça, no caso do nazismo. Ora, tal conhecimento não está atado à transcendência, pelo contrário, ele depende da interpretação inquestionável daquele que ocupa o poder, seja o partido, seja o líder. Em suma, a tentativa totalitária de fechar a sociedade sobre si mesma expressa um projeto de negação da própria ordem simbólica enquanto tal ao tentar solapar a referência à transcendência vazia e inocupável.

Essa experiência, contudo, especialmente no caso do stalinismo, mais detalhadamente estudado por Lefort, abarca uma série de contradições, as quais põem em risco a estabilidade do totalitarismo. A metáfora da máquina, neste caso, entra em confronto com a ideia de que cada membro da sociedade atua como um órgão do Povouno, ou seja, como um membro desse grande organismo, resultante de uma série de processos de identificação. Ao suspender qualquer referência à alteridade, o regime visa à representação tanto da cabeça do povo quanto deste em sua totalidade. Porém, corpo e máquina não podem atuar da mesma maneira, pois a imagem da máquina, atada à burocracia, não obedece à lógica de identificação constitutiva da imagem orgânica. Assim, a imagem contraditória de uma máquina organizada e organizável faz com que o corpo político se veja constantemente ameaçado por uma espécie de pulsão de morte. Essa ameaça restabelece a figura de um outro, apreendido como exterior ao corpo, mas que, na verdade, nada mais é do que o nome ou a figura fantasmática que o totalitarismo dá às correntes de divisão e de conflito presentes no interior da sociedade. Esse outro, imaginado como externo, embora sendo constitutivo do social, ameaça o corpo pelo intento de sabotar ou mesmo destruir as leis do regime. A equação segundo a qual é necessária uma constante profilaxia do corpo social por meio da eliminação daquilo que ameaça o plano de organização em curso, algo que precisa ser realizado pela burocracia que atravessa a organização de cada parte da sociedade, é a expressão máxima da negação de qualquer elemento dissidente. O contraditório aparece, então, como um inimigo do poder e, portanto, do corpo político enquanto tal. $O$ totalitarismo repele essa transcendência ameaçadora em nome da unidade fantasmática da sociedade. Se, na sociedade pré-moderna, a referência à transcendência era o polo simbólico produtor de uma unidade imaginária, no totalitarismo, ao contrário, a ocupação imaginária do lugar do poder pela sociedade inteira 
engendra a recusa e a necessidade constante de destruição de qualquer outro que possa ameaçar essa unidade. Sendo assim, o totalitarismo não é um retorno à pré-modernidade, mas sim uma tentativa de anular o dispositivo simbólico, marcado pela transcendência vazia do poder, o qual dá nascimento à modernidade. Ele não apenas preenche o lugar do poder, como também dissolve sua transcendência. Porém, esse regime, a despeito de suas pretensões de fechamento da sociedade em uma unidade sem fissuras, encontra-se sempre permeado pela contradição entre a máquina burocrática e o sistema de identificações que o figura como um grande organismo. Por isso, segundo Lefort, sua estabilidade nunca está garantida. Ao denegar o conflito, e ao suspender o dispositivo da transcendência, ele pretende também suspender o próprio movimento da história. Entretanto, como se pode testemunhar pelo terror responsável pela caça aos inimigos do regime, essa denegação não solapa por completo as divisões e as fissuras do tecido social, as quais dão indícios da impotência do regime para controlar e manter coesa a sociedade como um todo.

Podemos dizer, segundo os passos de Flynn, que a modernidade lida por Lefort é ela própria um dispositivo simbólico que pode ser vivido de duas maneiras: pode-se aceitar a mutação que o institui, e isto se faz no interior de um projeto democrático; ou se pode negá-lo, dando-se corpo ao projeto totalitário. Assim, desde Maquiavel, a modernidade exige uma resposta ao desafio colocado pela experiência da indeterminação que lhe dá origem e pela angústia que lhe sucede. É certo que o livro de Flynn nos dá uma visão articulada da obra de Lefort, especialmente por ser capaz de elucidar a investigação sobre o sentido profundo dessa experiência e de suas possíveis consequências. Assim, a junção entre a fenomenologia, filosofia que permite dissecar nosso acesso ao real ao interpretar a experiência vivida no interior desse novo dispositivo simbólico, e a leitura da tradição da filosofia política, capaz de fornecer o arsenal de conceitos apto a produzir uma interpretação dos acontecimentos que marcam a modernidade, produzindo, assim, a perspectiva de uma nova compreensão do político, dão o tom do trabalho desse importante intérprete do pensamento lefortiano. Trabalho minucioso, que, assim como a obra de Lefort, só a modernidade pode produzir e compreender. 


\section{BERNARD FLYNN, READER OF CLAUDE LEFORT}

Abstract: Claude Lefort is one of the most innovative political philosophers of our time. His work appears in great part, except for the book dedicated to Machiavelli, through the compilation of essays written in different periods and revolving around central problems, especially the characterization of democracy and totalitarianism. The task of producing a reading capable of giving meaning to this philosophical project, given its non-systematic character, is quite difficult. Thus, the work of Bernard Flynn is extremely fruitful for the interpretation of Lefort's thought. He argues that the combination of phenomenology, a philosophy that allows us to dissect our access to the real by interpreting the experience lived inside the democratic symbolic device, and the reading of the tradition of the political philosophy, capable of producing an interpretation of the events that mark modernity, allows Lefort to create a new understanding of the political. This paper intends to present the main aspects of this interpretation of the work of Lefort.

Keywords: Claude Lefort - Bernard Flynn - democracy - symbolic - imaginary - real.

\section{Referências bibliográficas}

CARDOSO, S. "Em direção ao núcleo da 'obra Maquiavel': Sobre a divisão civil e suas interpretações” In Revista Discurso, v. 45, n. 2, 2015, p. 207-247.

CHAUI, M. "Lefort: o trabalho da obra de pensamento" In Revista Discurso, v. 48, n. 1, 2018, p. 155-166.

CLASTRES, P. A sociedade contra o Estado. Pesquisas de antropologia política. Trad. De T. Santiago. São Paulo: Cosac Naify, 2012.

FLYNN, B. The Philosophy of Claude Lefort. Interpreting the Political. Evanston: Illinois: Northwestern University Press, 2005.

LA BOÉTIE, E. Discurso da Servidão Voluntária; [comentários] Pierre Clastres, Claude Lefort, Marilena Chaui. Trad. de L. Garcia dos Santos. São Paulo: Brasiliense, 1999.

LEFORT, C. A Invenção Democrática: os limites da dominação totalitária. Trad. de Isabel Loureiro e Maria L. Loureiro. Apresentação de Marilena Chaui. Belo Horizonte: Autêntica Ed., 2011.

Desafios da escrita política. Trad. de Eliana de M. Souza. São Paulo: Discurso Editorial, 1999.

Le travail de l'Euvre Maquiavel. Paris: Gallimard, 1972. 
Pensando o Político: ensaios sobre democracia, revolução e liberdade. Trad. de Eliana M. Souza. Rio de Janeiro: Paz e Terra, 1991.

Les formes de l'bistoire: essais d'anthropologie politique. Paris: Gallimard, 1978.

RAMOS, S. S. "Claude Lefort e a escrita democrática”, In Revista Discurso, v. 48, n. 1, 2018, p. 155-166. 